\section{Trimethylamine induces migration of waterfleas}

It has long been known that the waterflea Daphnia hyalina exhibits diel vertical migration in the water column, but the chemical that triggers this behaviour has not been identified. We find that trimethylamine (TMA), which is a major component of the odour produced by decaying fish, induces Daphnia to migrate to greater depths during the day, presumably to avoid predation by fish ${ }^{1,2}$. We observed a gradual increase in average depth of Daphnia with increasing TMA concentration. Changes in light intensity are known to trigger migration $^{3}$, and chemicals produced by their predators must also be present ${ }^{4}$. Because migration has demographic and physiological costs, this chemical cue ensures that zooplankton migration occurs only when fish are present.

It has been shown that, whatever the migration trigger substance may be, it is produced only by fish in the presence of bacteria. This led to the hypothesis that trimethylamine- $N$-oxide (TMAO), which is important for cell volume regulation ${ }^{5}$ and protein stabilization ${ }^{6}$ in marine and freshwater fish, could be a precursor of the kairomone. Surplus TMAO is deposited in fish scales ${ }^{7}$, and bacteria of the skin mucus layer are known to reduce TMAO to TMA ${ }^{8}$.

We tested the hypothesis that TMA induces vertical migration in Daphnia by using a range of different concentrations, from 0 to $500 \mu \mathrm{M}$ TMA, in autoclaved lake water $^{9}$ (Fig. 1). Five individuals of a single Daphnia hyalina clone were put into each of four Perspex tubes $(1 \mathrm{~m}$ long and $1.5 \mathrm{~cm}$ in

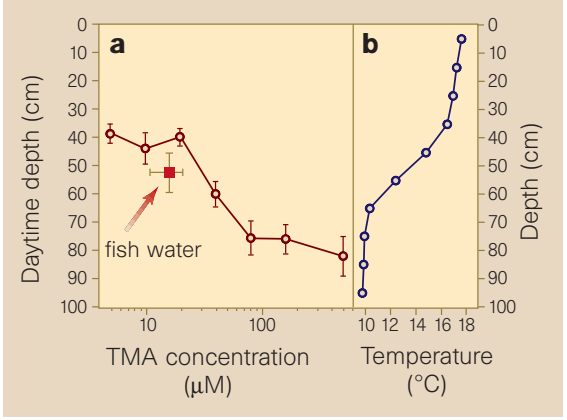

Figure 1 Behavioural responses of Daphnia hyalina to trimethylamine. a, Average day depth ( \pm standard error) of five daphnids (four replicates per treatment) on three consecutive days of different TMA concentrations. The day:night cycle was 16:8 hours. The reaction of the daphnids is plotted against the concentration of TMA in fish water. Bacterial decay of TMA was prevented by the addition of ampicillin. Migration depth increased in all tubes from day 1 to day 3. b, Temperature profile of the tubes. As TMA concentration increases, daphnids migrate to greater depths and colder water during the day. diameter) per treatment. The tubes were then placed in a water bath with a temperature gradient from top to bottom of 20 to $10{ }^{\circ} \mathrm{C}$. We used a spectrophometric assay procedure $^{10}$ to establish the TMA concentration in 10 litres of the medium that had previously contained four fish (ides, Leuciscus idus, $10 \mathrm{~cm}$ long), and recorded the resulting vertical migration behaviour of daphnids exposed to this medium. TMA concentration in this 'fish' water was between 10 and $25 \mu \mathrm{M}$.

We found that even low concentrations of TMA induce Daphnia to migrate to deeper waters during the day in our test system. At night, they migrate back to the surface when exposed to small amounts of TMA, and stay near the bottom when TMA levels are high (more than $100 \mu \mathrm{M}$ ). When the lowest TMA concentration that induces vertical migration is compared with the activity in the fish water, it is clear that the reaction of Daphnia to fish water is stronger than just to TMA alone. This indicates that, although TMA is an active component of the 'fish factor', it is likely to be part of a cocktail of substances that deter Daphnia. The other substances probably help to reduce the chemical threshold that induces migration. It is not clear whether the TMA concentrations used in this study represent realistic values for aquatic systems, as we could find no published details of TMA concentrations in aquatic systems.

It has been shown ${ }^{9}$ that the fish kairomone is broken down by bacteria. We therefore compared the average day depth of daphnids exposed to $75 \mu \mathrm{M}$ TMA in autoclaved water, and with the antibiotic ampicillin added and the TMA dissolved in non-autoclaved lake water. The migration activity of the Daphnia in non-sterile water slowly decreased over time (Fig. 2). After 72

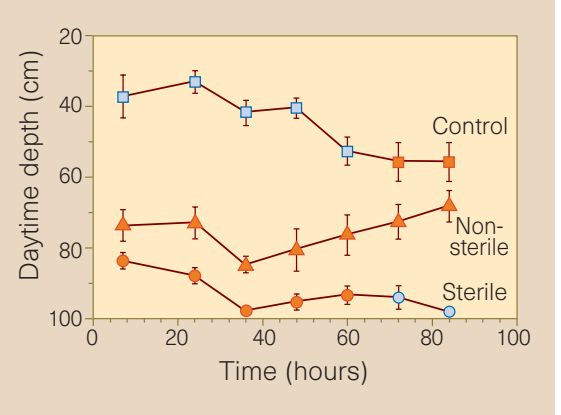

Figure 2 Average day depth ( \pm s.e.) of five daphnids. There were eight replicates per treatment. Symbols with different colours indicate significant differences between the treatments (Tukey post hoc comparison after analysis of variance, with treatment as a factor and time as a repeated measurement factor). Sterile and non-sterile treatments are not significantly different from each other, but were significantly different from the control for the first 60 hours; after 72 hours, daphnids kept under sterile conditions are significantly deeper than the control animals and those kept under non-sterile conditions. hours, the average day depth of the animals in non-sterile conditions was no longer significantly different from the average day depth of animals in sterile control medium.

To investigate whether simply adding any substance to the water induces vertical migration, we added the same amount of TMAO and triethylamine to sterile water (both at $75 \mu \mathrm{M}$ ). As with the control Daphnia, there was no significant increase in day depth. We therefore conclude that the reaction to TMA is a specific one, and not simply a response to a change in conductivity or ionic strength of the medium.

Hinnerk Boriss, Maarten Boersma,

\section{Karen H. Wiltshire}

Max-Planck-Institut für Limnologie,

Postfach 165, 24302 Plön, Germany

e-mail: boriss@mpil-ploen.mpg.de

1. Stich, H. B. \& Lampert, W. Nature 293, 396-398 (1981).

2. Gliwicz, M. Z. Nature 320, 746-748 (1986).

3. Ringelberg, J. J. Mar. Biol. Assoc. UK 75, 15-25 (1995).

4. Larsson, P. \& Dodson, S. Arch. Hydrobiol. 129, 129-155 (1993)

5. Lange, R. \& Fugelli, K. Comp. Biochem. Physiol. 25, 283-292 (1965).

6. Yancey, P. H. \& Somero, G. N. Biochem. J. 183, 317-323 (1979).

7. Hill, R. W. Comparative Physiology of Animals (Harper \& Row, New York, 1976).

8. Gram, L., Wedell Neergaard, C. \& Huss, H. H. Int. J. Food Microbiol. 10, 303-316 (1990).

9. Loose, C. J., von Elert, E. \& Dawidowicz, P. Arch. Hydrobiol. 126, 329-337 (1993).

10. Kakác, B. \& Vejdelek, Z. J. Handbuch der Photometrischen Analyse Organischer Verbindungen (Chemie, Weinheim, 1974)

\section{Ancient stunted trees on cliffs}

An undisturbed ancient woodland, dominated by tiny, slow-growing and widely spaced trees, grows on vertical cliffs of the Niagara escarpment in southern Canada ${ }^{1}$. To investigate whether this woodland is unusual or is part of a previously undetected global pattern, we sampled ages and radial growth rates for trees on cliffs in the United States and in western Europe. We find that vertical cliffs often support populations of widely spaced trees that are exceptionally old, deformed and slow growing. Some of the most ancient and least-disturbed wooded habitat types on Earth are found on cliffs, even at sites close to heavy agricultural and industrial development.

We selected 21 cliffs for sampling in 15 eastern states of the United States, and 25 cliffs in eastern and southern Germany, eastern and southern France, central and northern England and Wales. All areas have been heavily developed for industry and agriculture over a long time. The cliffs visited were at least 500 metres long and between 20 and 1,500 metres high. We extracted increment cores for analysis from near the base of 224 mature trees. Some individual living trees grew as thin stemstrips on large amounts of dead wood. We 

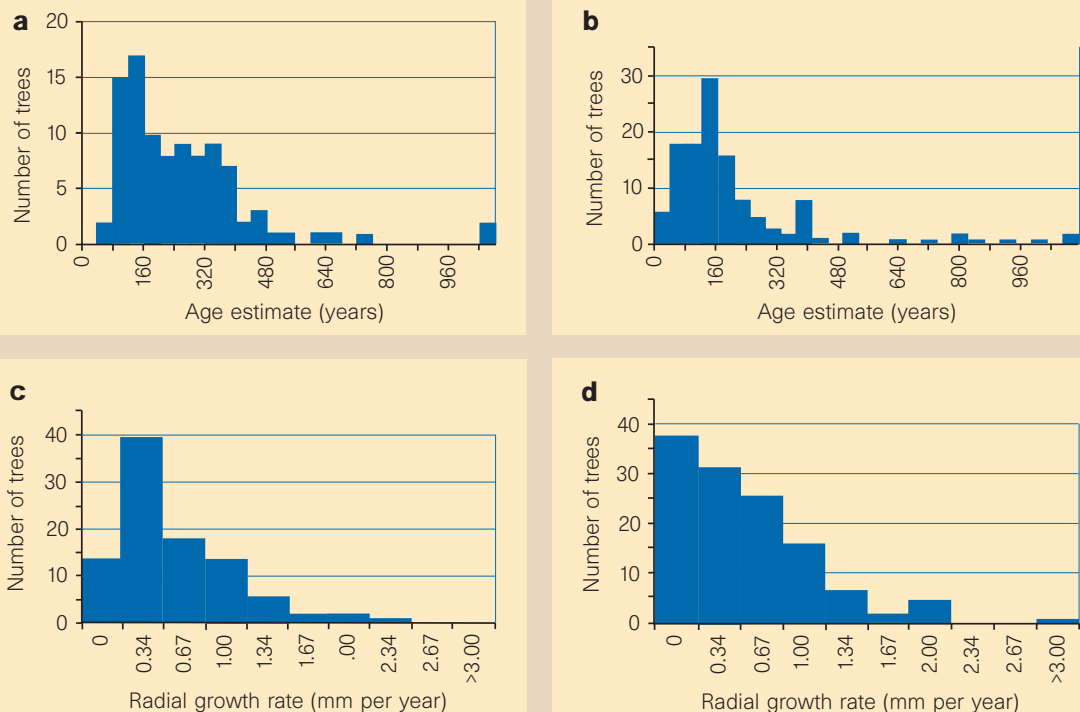

Figure 1 Age estimates and growth rates of trees on cliffs. Frequency distributions of estimated tree ages (a, b) and radial growth rates $(\mathbf{c}, \mathbf{d})$ for mature trees growing on cliffs in the United States $(\mathbf{a}, \mathbf{c}, n=97)$ and Europe (b, d, $n=127)$.

sometimes took cross-sections from the dead parts of these trees to allow for more accurate dating of core samples extracted from the living portions.

We recorded the diameter of each tree and the location of the pith for more accurate age estimations when core samples did not include the pith$^{2}$. We then used the distance from the cambium to the youngest ring to calculate radial growth rate, expressed as millimetres of new wood per year. All sample cores or sections were mounted and sanded ${ }^{3}$. Results were plotted as frequency distributions for both age estimate and growth rate, and US and European results were compared using non-parametric tests ${ }^{4,5}$. For age estimates, we expected to find evidence of a negative exponential frequency distribution if the mature trees on the cliffs were part of a selfmaintaining natural woodland ${ }^{6}$. For growth rate, we expected to find a tight clustering of very low values if the mature trees were highly constrained in their productivity ${ }^{7}$.

Most of the US trees sampled are between 160 and 400 years old, with two trees being more than 1,000 years old and very few less than 100 years old. The trees were mainly Thuja occidentalis in the northern states and Juniperus virginiana in the rest. Despite our non-random sampling, the portion of the curve above 80 years of age has the shape of a negative exponential (Fig. 1a). European trees also have a negative exponential age distribution when the youngest age category is excluded (Fig. 1b), and some J. phoenicea and Taxus baccata trees in France and the United Kingdom, respectively, were more than 1,000 years old. We found unevenly aged living tree populations on all cliffs, and observed coarse woody debris in a variety of decay states. The findings indicate that the populations on both continents have remained undisturbed for long periods, and have had continuous, rather than pulsed, recruitment over the past millennium.

Radial growth rates for trees in the United States (Fig. 1c) and Europe (Fig. 1d) were mostly less than 1 millimetre per year, similar to the rate for trees growing on the Niagara escarpment ${ }^{1}$. They must be some of the slowest-growing woody plants on Earth. All the trees were grossly deformed as well as stunted. A 1.5-metre-tall, 1,140year-old J. phoenicea tree, for example, from the Verdon Gorge, France, had a radius of nearly $8 \mathrm{~cm}$ and an annual radial growth rate slightly more than $0.06 \mathrm{~mm}$. Its axial morphology was typical of cliff trees in exhibiting partial cambial mortality and an inverted morphology. All core samples from cliff-face trees showed radial growth rates that were the same in the sapling and the mature stages of development.

The ages of the trees may indicate the ages and growth rates of the entire plant communities on the cliffs. Cliffs across the world may support ancient, slow-growing, open woodland communities that have escaped major human disturbance, even when they are situated close to agricultural and industrial activity, which has destroyed or altered most other natural habitats ${ }^{8-10}$.

D. W. Larson*, U. Matthes*, J. A. Gerrath*, J. M. Gerrath $\dagger$, J. C. Nekola $\neq$, G. L. Walker§, S. Porembskif, A. Charlton\#,

N. W. K. Larson ${ }^{\star}$

${ }^{\star}$ Cliff Ecology Research Group,

University of Guelph,

Guelph, Ontario, N1G 2W1, Canada

e-mail:dwlarson@uoguelph.ca $\dagger$ Department of Biology,

University of Northern Iowa,

Cedar Falls, Iowa 50614, USA

\$Department of Natural and Applied Sciences, University of Wisconsin,

Green Bay, Wisconsin 54311, USA

$\$$ Department of Biology,

Appalachian State University,

Boone, North Carolina 28608, USA

gotanisches Institut, University of Bonn,

53115 Bonn, Germany

\#Department of Biology, University of Manchester, Manchester M13 9PT, UK

1. Larson, D. W. \& Kelly, P. E. Can. J. Bot. 69, 1628-1636 (1991).

2. Kelly, P. E. \& Larson, D. W. J. Ecol. 85, 467-478 (1997).

3. Kelly, P. E., Cook, E. R. \& Larson, D. W. Can. J. Forest. Res. 24 , 1049-1057 (1994).

4. Zar, J. H. Biostatistical Analysis (Prentice-Hall, Englewood Cliffs, NJ, 1974).

5. Conover, W. J. Practical Non-parametric Statistics 2nd edn (Wiley, New York, 1971).

6. Hett, J. M. \& Loucks, O. L. J. Ecol. 64, 1029-1044 (1976).

7. Kelly, P. E., Cook, E. R. \& Larson, D. W. Int. J. Plant Sci. 153, 117-127 (1992).

8. Vitousek, P. M. Ecology 75, 1861-1876 (1994).

9. Spencer, J. W. \& Kirby, K. J. Biol. Conserv. 62, 77-93 (1992).

10. Peterken, G. F. Natural Woodland (Cambridge Univ. Press. 1996).

\section{Molecular basis of triclosan activity}

Triclosan (5-chloro-2-(2,4-dichlorophenoxy) phenol) has been used for more than 30 years as a general antibacterial and antifungal agent, and is found in formulations as diverse as toothpastes, cosmetics, antiseptic soaps, carpets, plastic kitchenware and toys. It has recently been suggested that triclosan blocks lipid biosynthesis by specifically inhibiting the enzyme enoyl-acyl carrier protein reductase $(\mathrm{ENR})^{1}$. We have carried out a structural analysis and inhibition experiments on a complex of ENR from the bacterium Escherichia coli with triclosan and $\mathrm{NAD}^{+}$. We find that triclosan acts as a sitedirected, very potent inhibitor of the enzyme by mimicking its natural substrate.

ENR catalyses the final, regulatory step in the fatty-acid synthase cycle: the reduction of a carbon-carbon double bond in an enoyl moiety that is covalently linked to an acyl carrier protein. ENR has been identified as a target for the diazaborines ${ }^{2}$, a family of antibacterial agents, and many triclosanresistant strains of $E$. coli have been found to be resistant to diazaborines ${ }^{1}$.

The structure of the E.coli ENR complexed with $\mathrm{NAD}^{+}$and triclosan (triclosan was provided by Ciba Speciality Chemicals and Coalite Chemicals) was determined to $2.2 \AA$ resolution. The electron density map of the complex is of high quality (Fig. 1a) and reveals the mode of binding of the triclosan adjacent to the nicotinamide ring of the nucleotide cofactor in the enzyme's active site. The phenol ring of triclosan forms a face-to-face interaction with the 